\section{Esterification of Phthalic Anhydride with Primary Alcohols at Room Temperature}

IN a recent publication ${ }^{1}$, some investigations on the esterification-rate of dibasic acid anhydrides with primary alcohols at room temperature were recorded. From the results of titration of acid anhydrides dissolved in the cold in primary alcohols, using a solution of potassium hydroxide in the alcohol as titrating agent, it was concluded that mono-ester formation was instantaneous and quantitative, being so rapid that comparison of rates of reaction was impossible.

We have attempted to utilize this apparently instantaneous reaction in the preparation of certain half-esters of phthalic acid, but soon discovered that the expected product was only obtained in very small yields, if at all. Even after prolonged periods, substantial amounts of unchanged phthalic anhydride were recovered from the mixture. Titration of the mixture by the method of Siagel and Moran did, however, give results in agreement with the formation of a half-ester.

We consider that these apparently contradictory findings become reconciled if the esterification reaction is catalysed by the addition of the titrating agent. It is therefore incorrect to conclude that mono-esterification of a dibasic acid anhydride with a primary alcohol proceeds instantaneously and quantitatively at room temperature, as it only does so after the addition of potassium hydroxide, that is, in the presence of a catalyst.

\section{F. J. Bristow}

Imperial Chemical Industries, Ltd.,

(Paints Division),

Wexham Road,

Slough.

July 14.

${ }^{1}$ Siegel, E. F., and Moran, M. K., J. Amer. Chem. Soc., 69, 1457 (1947).

\section{Photolysis of Organic Disulphides}

THE reactions following light absorption by pure organic disulphides in solution have not been studied, although the reactions are of great importance in the chemistry of wool, affecting both felting and shrinkage of the wool $^{1,2}$. Similar reactions occur in irradiated milk $^{3}$ and in petrol 4 .

The absorption spectra of diphenyl-, di-o-tolyl-, and di-p-tolyl-disulphides were found to be similar. Absorption occurred below c. 3,000 A., with $\lambda_{\max .}=$ $2,450 \mathrm{~A}$.

Solutions of all three in organic solvents, as well as cystine in 3 per cent hydrochloric acid, were ex. posed to filtered light from a 125.W. mercury vapoir street lamp from which the glass envelope had been removed. Measurements of the light flux by uranyl oxalate actinometry gave results in good agreement with those obtained using a thermopile-galvanometer combination. It was found that the disulphides were converted into the ecrresponding thiols, identified by the melting points of their metallic derivatives and estimated by amperometric titration with silver nitrate. The solvent was variously alcohol, $n$-hexane and ether.

In view of the theory ${ }^{1,2}$ which accounts for the acidity developed in irradiated wool by the presence of sulphuric acid produced from hydrogen sulphide, which in turn came from a disulphide by photochemical reaction, tests were made repeatedly to determine whether hydrogen sulphide was a product in these reactions also; but no trace of any was found. Nor was sulphur a product, air having been excluded from the reaction vessel.

The quantum yield of thiol formation was $0 \cdot 046 \pm$ 0.003 for diphenyl-, di-o-tolyl- and di-p-tolyldisulphides respectively, and 0.020 for cystine in hydrochloric acid. It was independent within experimental error $(a)$ of the nature of the aryl group, (b) of the concentration of the disulphide, and (c) of the nature of the solvent used. The lower value for the cystine is explained by the simultaneous liberation of ammonia in this case

The following mechanism is adequate if a free radical $R-\mathrm{S}-$ be assumed formed, as has been done in another case ${ }^{6}$. Free-radical formation is energetic. ally possible with light of wave-length less than $4470 \mathrm{~A}$., taking the energy of the SS bond to be $63 \cdot 8 \mathrm{k} . \mathrm{cal} . / \mathrm{mole}$.

$$
\begin{aligned}
& R-\mathrm{S}-\mathrm{S}-R \quad \stackrel{h v}{\rightarrow} R-\mathrm{S}-\mathrm{S}-R^{*} \\
& \begin{array}{ll}
R-\mathrm{S}-\mathrm{S}-R & \rightarrow R-\mathrm{S}-R^{*} \\
R-\mathrm{S}-\mathrm{S}+M & \rightarrow R-\mathrm{S}- \\
R-\mathrm{S}-\mathrm{S}-R^{*}+M & \rightarrow R-\mathrm{SH} \\
\end{array}
\end{aligned}
$$

where $M$ is a solvent molecule. Reaction $D$ explains the fact that the quantum yield of thiol formation is less than 1. Its value indicates that an activated molecule has one chance in $\mathbf{4 4}$ of decomposing before it is deactivated by collision.

I am indebted to the Commonwealth Research Committee for a grant which made possible the purchase of equipment used.

Department of Chemistry,

W. E. Lyons

University, Sydney.

$$
\text { July } 5 .
$$

1 McMahon, P. R., and Speakman, J. B., Trans. Farad. Soc., 33, 844 (1937).

${ }^{2}$ Harris, M. L., and Smith, A. L., J. Res. Bureau Standards, 20, 563 (1938).

Flake, J. C., Jackson, H. C., and Weckel, H. G., Chem. Abs., 35, 2228 (1941). - Morrell, J. C., Benedict, W. I., and Egloff, G., Ind. Eng. Chem.,
28, 122 and 448 (1936).

${ }^{5}$ Lieben, F., and Urban, F., Biochem. Z., 289, 250 (1931).

6 Waters, W. A., "Chemistry of Free Radicals", 73 (1946).

\section{"Pre-Natal Physiology"}

IN his comprehensive and excellent review of Sir Joseph Barcroft's "Researches on Pre-Natal Life" which appeared in Nature, 159, p. 383, Dr. F. H. A. Marshall makes the following statement: "With regard to the matter of permeability the author finds that, contrary to the views of Flexner, the greater the number of layers in the fœetal barrier, the more perfect is the foetus at birth, . . .". On page 5 of his book, Sir Joseph states that my colleagues and I were interested in placental permeability rather than placental 'efficiency'. I should like to point out that we have made no statements about a possible correlation between placentul structure and the maturity of the fotus at birth, and there is consequently no conflict with Sir Joseph's views on this matter.

Department of Embryology, Louis B. FLEXNER

Carnegie Institution of Washington, Baltimore, Maryland. 